\title{
Anxiety and depression over the first year of spinal cord injury: a longitudinal study
}

\author{
K M Hancock BSc MAPS, ${ }^{1}$ A R Craig BSc PhD MAPS,${ }^{2} \mathrm{H}$ G Dickson MB BS \\ FACRM ${ }^{3}$ E Chang RN, ${ }^{4} \mathrm{~J}$ Martin $\mathrm{PhD}^{5}$
}

${ }^{1}$ Scientific Officer, ${ }^{2}$ Senior Lecturer and Clinical Psychologist, School of Nursing Health Studies, University of Technology, Sydney; ${ }^{3}$ Director, Department of Rehabilitation and Geriatrics, Liverpool Hospital, Sydney; ${ }^{4}$ Senior Lecturer, Faculty of Nursing, University of Technology, Sydney; ${ }^{5}$ Senior Lecturer, Department of Counselling and Disability Studies, University of Western Sydney, Nepean, Sydney, Australia.

The literature concerning the psychological consequences following spinal cord injury (SCI) indicates a discordance between clinical impressions and empirical research. Although many studies report that psychological morbidity is not an inevitable consequence of SCI, much of this research is characterised by methodological inadequacies and the conclusions are therefore tenuous. The present study assessed 41 persons with SCI for depression and anxiety using objective psychological measures on three occasions over the first year of SCI and compared them with 41 able bodied controls matched for age, sex, education and, as far as possible, occupation. Results demonstrated significant differences between the two groups, with the SCI group being more anxious and depressed. However, psychological morbidity was not an inevitable consequence of SCI, with group means reflecting mild levels of depression and anxiety. No significant differences were found across time and no interactions between groups and time were detected. Implications for the treatment of SCI are discussed.

Keywords: spinal cord injury; psychological adjustment; anxiety; depression.

\section{Introduction}

The traumatic nature of spinal cord injury (SCI) necessitates considerable changes in a person's life depending on the extent of the loss. Apart from immobility and loss of sensation, there may also be unpleasant additional effects including impaired sexual function, incontinence and pain. These physical symptoms often result in vocational and social losses and place great demands on family roles and relationships. Given these problems, one would suspect psychological disruption to be common following SCI. Previous opinions viewed depression as an almost inevitable consequence, ${ }^{1-5}$ and suggested that denial was occurring if a patient was not experiencing depression. However, these views were mainly based on

Correspondence: Ms K Hancock, UTS, PO Box 123 Broadway, NSW 2007, Australia. subjective, anecdotal evidence rather than on empirical evidence.

The literature concerning the psychological consequences of spinal injury has seen an increasing trend over the last few decades towards the use of more objective measures of psychological distress rather than reliance on clinical experiences. A literature review conducted by the authors ${ }^{6}$ regarding studies investigating the psychological consequences of spinal injury suggested that conflict exists between clinical impressions and objective based research. Empirical studies report depression to be present in only $20-45 \%$ of patients, ${ }^{7-9}$ indicating that severe psychological disruption is not an inevitable consequence of SCI.

The belief that clinical impressions may overestimate psychological disruption is suggested by studies investigating differences between staff ratings and patient 
ratings of depressed mood. ${ }^{10-12}$ Furthermore, health professionals differ between themselves in their assessment of SCI persons. Research by Dijkers and Cushman ${ }^{13}$ found that mental health professionals and physicians reported the lowest, occupational and physiotherapists occupied an intermediary position, and nurses judged the highest percentage of patients as being depressed.

While these findings suggest that caution should be exercised in accepting clinical impressions, methodological problems in the objective-based research also suggest caution in the interpretation of the empirical findings. To date, there are few controlled studies investigating the psychological impact of SCI. For example, while research suggests that several demographic variables may influence the response to SCI, very few studies have had controls for these variables by employing a control group matched according to these factors (eg age, sex, education). In addition, the literature is characterised by a lack of longitudinal research. Psychological measures are often taken on only one occasion during the patient's rehabilitation, preventing the assessment of changes in adjustment that may occur over time. Many researchers have attempted to investigate the long term impact of SCI by comparing a group of long term injured subjects with newly injured patients, which implies that the population of persons with SCI is a homogeneous one. However, homogeneity in SCI populations has not been demonstrated. ${ }^{14}$ Further, subject numbers are often low, reducing the power of the research. Another methodological problem with many empirical studies concerns their failure to define adjustment or depression. Some use the term in a clinical sense while others may be referring to feelings of despondency or sadness which may not necessarily be reflective of clinical depression.

Suicide and divorce rates amongst people with SCI are on the increase. ${ }^{15}$ These indicators of long term adjustment suggest that it is important to better understand the psychological consequences following SCI. It is also important to identify those individuals who are at risk of complicated adjustment, such as being depressed and anxious, ${ }^{16}$ by examining the contribution of various demographic and social factors to the degree of psychological distress experienced following SCI. Some variables that have been found to be associated with an unfavourable adjustment to SCI include older age, low education, low social support, being male, and having a complete lesion. ${ }^{4,17}$ Although attempts to isolate factors associated with unsuccessful adjustment to SCI have been studied in the past, inadequacies in methodology such as those mentioned limit the validity of the findings.

The following is a report of a controlled longitudinal study investigating the psychological impact of a spinal cord injury. The study was designed to assess objectively the extent of SCI persons' depression and anxiety over the first year in comparison to an able bodied control group matched for age, sex, education and, as far as possible, occupation. Factors contributing to an unfavourable outcome were also investigated.

\section{Method}

\section{Spinal cord injured group}

Subjects in this group included persons sustaining an acute SCI admitted to a SCI ward. They were invited to participate when they were mobile in a wheelchair and attending rehabilitation therapies. Only subjects who were newly injured, had permanent neurological loss, had no head injuries or any preexisting psychopathology (as determined by the nursing unit manager's report), were at least 17 years of age, and able to speak English were selected for the study. Altogether 48 suitable SCI patients out of a total of 99 patients with permanent loss were invited to participate, representing a one year admission to each of the Sydney teaching hospital acute SCI units. Twenty-five subjects were admitted to the first spinal unit in 1989 and 23 admitted to the second spinal unit in 1990 . Of those 48,4 declined the request to participate, 2 failed to complete the research and one regained enough movement to walk unaided, and thus had to be excluded from the research (as the research is aimed at SCI persons who are wheelchair-bound). The 
final sample consisted of a total of 41 subjects. Although the sample was obtained from two units, the two units were similar in terms of rehabilitation schedules, length of stay and care philosophies. One minor difference was that patients were transferred to a different unit at one of the hospitals upon entering the rehabilitation phase. However, rehabilitation practices did not differ significantly between the two hospitals. Furthermore, no significant differences were found between the two groups in terms of psychological morbidity (as measured by the standardised instruments employed) and demographics such as sex, age and education. Therefore the two groups were combined as one sample for this study.

\section{Control group}

The controls were a group of able bodied persons matched to the SCI group for age, sex, education and, as far as possible, occupation. Subjects who volunteered were recruited from technical colleges, hospital ancillary staff, and acquaintances known to the research team to fit the selection criteria. To limit bias in the selection process, and ensure a truly matched sample, the controls were selected on a case by case basis, entirely upon whether they were of the same age (within 5 years), sex and had similar education/occupation. The authors were satisfied that this was achieved. Of course, controls could not be those with permanent injury or those with a prior history of psychopathology (as in the SCI group). The time frame for assessment was the same as for the SCI group.

\section{Demographic characteristics}

Subjects were 34 men and 7 women with a mean age of 31 years, ranging from 17 years to 73 years $(\mathrm{SD}=14)$. The sample were mainly Australian-born (75\%), with a minority born overseas $(10 \%$ from western, English-speaking countries, $10 \%$ from Asia and 5\% from western, non English speaking countries). Religious beliefs were predominantly agnostic $(59 \%)$, followed by Christian $(41 \%)$. Fifty-six percent were single and $34 \%$ married. Education stand- ard consisted mainly of 10 years of schooling or less $(66 \%)$, with $15 \%$ having a diploma or trade qualification, $7 \%$ obtaining higher school certificate and $12 \%$ having a university degree or higher. Occupations consisted primarily of trade and unskilled jobs (73\%), with $17 \%$ having clerical occupations and $10 \%$ having professional backgrounds.

\section{Injury characteristics}

The sample was evenly divided in terms of severity of injury, with $21(51 \%)$ diagnosed as paraplegic and $20(49 \%)$ as quadriplegic. No significant differences were found between the two groups in terms of demographics or overall scores on the psychological measures used for this study (see Table I), so they were combined as one sample. The majority of subjects $(68 \%)$ had complete lesions, while $32 \%$ were incomplete. Complete and incomplete lesions were almost evenly divided between paraplegia and quadriplegia (54\% paraplegia for complete lesions, $46 \%$ paraplegia for incomplete). All injuries were traumatic in nature. The major cause of injury was motor vehicle accidents $(44 \%)$, followed by falls $(24 \%)$ and sporting accidents (17\%).

\section{Measures}

Following their consent subjects were assessed on three occasions: approximately 2 weeks following placement in a wheelchair (usually 2-4 months post injury); 2 weeks prior to discharge from hospital or 3-4 months following the first assessment (whichever came first); and 6 months following the second assessment (usually one year post injury). The acute stage of SCI is often one dominated by bed rest, sedation and lack of sensory stimulation, and it is therefore often difficult to obtain a useful report of a patient's psychological status at this time. Therefore no assessment took place at this stage. Nursing and medical staff indicated that the first occasion selected was a more appropriate time for assessment. The transition from bed to wheelchair is the time when many patients realise the implications of their injury and the long struggle they have to face in terms of rehabilitation. 
Table I Means, standard deviations and $t$ values for persons with paraplegia and quadriplegia. Alpha was set at 0.01 due to multiple testing

\begin{tabular}{|c|c|c|c|c|c|}
\hline \multirow{2}{*}{$\begin{array}{l}\text { Var } \\
\text { ANX1 }\end{array}$} & \multirow{2}{*}{$\frac{\begin{array}{c}\text { 2-tailed } \\
t\end{array}}{1.3}$} & \multirow{2}{*}{ } & \multicolumn{2}{|c|}{$\begin{array}{c}\text { Paraplegia } \\
(n=21)\end{array}$} & \multirow{2}{*}{$\begin{array}{c}\begin{array}{c}\text { Quadriplegia } \\
(n=20)\end{array} \\
\begin{array}{c}38.1 \\
(8.4)\end{array}\end{array}$} \\
\hline & & & $\begin{array}{l}41.8 \\
(9.2)\end{array}$ & $\begin{array}{c}\text { mean } \\
\text { SD }\end{array}$ & \\
\hline ANX2 & 2.1 & 0.05 & $\begin{array}{c}41.4 \\
(10.1)\end{array}$ & $\begin{array}{c}\text { mean } \\
\text { SD }\end{array}$ & $\begin{array}{c}34.6 \\
(11.5)\end{array}$ \\
\hline ANX3 & 0.3 & 0.74 & $\begin{array}{c}37.2 \\
(10.1)\end{array}$ & $\begin{array}{c}\text { mean } \\
\text { SD }\end{array}$ & $\begin{array}{c}36.1 \\
(11.9)\end{array}$ \\
\hline BDI1 & 1.4 & 0.16 & $\begin{array}{l}11.9 \\
(6.4)\end{array}$ & $\begin{array}{c}\text { mean } \\
\text { SD }\end{array}$ & $\begin{array}{c}9.0 \\
(6.6)\end{array}$ \\
\hline BDI2 & 1.1 & 0.26 & $\begin{array}{l}11.4 \\
(7.9)\end{array}$ & $\begin{array}{c}\text { mean } \\
\text { SD }\end{array}$ & $\begin{array}{c}8.4 \\
(9.2)\end{array}$ \\
\hline BDI3 & -0.01 & 0.98 & $\begin{array}{c}8.9 \\
(7.7)\end{array}$ & $\begin{array}{c}\text { mean } \\
\text { SD }\end{array}$ & $\begin{array}{c}9.0 \\
(10.2)\end{array}$ \\
\hline
\end{tabular}

The role of social support in influencing adjustment to SCI was assessed on the three occasions by a 6 point Likert-type social support scale. The scale consisted of seven items indicating the degree to which patients agreed or disagreed $(1=$ strongly agree, $6=$ strongly disagree) that family and friends had been supportive in terms of offers of help and assistance as well as acceptance of them as a person with spinal injury.

A comprehensive battery of instruments was used to assess the extent of psychosocial morbidity. For this study only the Beck Depression Inventory (BDI $)^{18}$ and The Spielberger State-Trait Anxiety Inventory (STAI) ${ }^{19}$ will be reported. The BDI is a well validated self-report measure of depression, consisting of a list of 21 descriptive statements assessing symptoms of depression. Other research into depression following SCI has found the BDI to be a good screening instrument and it has been shown to be sensitive to change. ${ }^{20}$ The STAI is a 20 item self-report measure of trait anxiety. It has been widely used with well demonstrated reliability and validity.

\section{Statistical analysis}

Data were analysed using a repeated measures analysis of variance to test for differences between groups and changes over time. Independent $t$-tests were performed to determine if there were any differences between (1) persons with paraplegia and quadriplegia and (2) persons with complete and incomplete lesions on anxiety and depression scores. As a greater chance of obtaining a type I error (the chance of falsely rejecting the null hypothesis) exists in multiple $t$-testing, the traditional alpha rate of 0.05 was changed to 0.01 .

Pearson correlations were computed to determine associations between patient characteristics and the anxiety and depression measures across the three occasions.

\section{Results}

Table II presents mean depression and anxiety scores over the first year of injury. Significant differences were found between the spinal injured and control groups on anxiety and depression $(\mathrm{F}(1,80)=6.9$ $p<0.01$ for anxiety; $\mathrm{F}(1,80)=29.27, p<$ 0.01 for depression), with the SCI group being more anxious and depressed than the control group. There were no significant differences overall across time for anxiety or depression $(\mathrm{F}(2,160)=1.9 ; p=\mathrm{NS}$ for anxiety; $\mathrm{F}(2,160)=2,26 ; p=\mathrm{NS}$ for depression), nor were there any significant interactions present between group and time $(\mathrm{F}(2,160)=1.4 ; p=\mathrm{NS}$ for anxiety; $\mathrm{F}(2,160)=08 ; p=\mathrm{NS}$ for depression). 
Table II Depression and anxiety means and standard deviations for SCI and controls. BDI1 is Beck Depression Score on the first assessment, BDI2 is the second and BD13 the third depression assessment. ANX1 is Spielberger Trait Anxiety score on the first assessment, ANX2 is the second and ANX3 is the third anxiety assessment

\begin{tabular}{|c|c|c|c|c|}
\hline \multirow[b]{2}{*}{ Scale } & \multicolumn{2}{|c|}{ SCI } & \multicolumn{2}{|c|}{ Controls } \\
\hline & Mean & $\mathrm{SD}$ & Mean & SD \\
\hline BDI1 & 10.5 & 6.6 & 3.9 & 4.7 \\
\hline BDI2 & 9.9 & 8.6 & 3.2 & 4.4 \\
\hline BDI3 & 9.1 & 8.8 & 2.4 & 2.4 \\
\hline ANX1 & 40.0 & 8.9 & 34.4 & 7.4 \\
\hline ANX2 & 38.0 & 11.1 & 33.4 & 8.4 \\
\hline ANX3 & 36.8 & 10.7 & 34.2 & 6.9 \\
\hline
\end{tabular}

Given that there were no significant differences in scores across time, the three scores for each dependent variable were averaged to provide an overall index of each score over the year. For averaged anxiety scores, subjects were dichotomised into one of two groups, those falling in the normal range for that measure (as reflected in general population norms for the instrument) and those falling one standard deviation above the normal cut-off score $(>42)$. This gives an indication of the frequencies of subjects with abnormal psychological responses. Although mean anxiety levels for both groups were within one standard deviation of means found in the general population, Table III demonstrates that averaged over the year, approximately $25 \%$ of the spinal injured subjects had trait anxiety scores which were at least one standard deviation above normal levels ${ }^{19}$ compared to only $5 \%$ of control subjects $\left(X^{2}=6.25 ; p<0.02\right)$. For the BDI, a score of 14 on the BDI has been found to differentiate between depressives and non depressives. ${ }^{18}$ Using a cut off score of greater than 14 (Table III), approximately $27 \%$ were clinically depressed averaged over the year, whereas approximately $3 \%$ of controls fell into this category $\left(X^{2}=9.76, p<0.01\right)$.

Table IV shows $t$-test results which indicate no significant differences on any of the anxiety or depression measures for complete versus incomplete lesions. Similarly, Table $\mathrm{V}$ shows no significant differences between persons with paraplegia and those
Table III Chi-square analysis showing differences between the SCI and control group on frequencies of normal and abnormal anxiety scores. Those subjects scoring less than or equal to 42 were considered normal in their anxiety, whilst those scoring greater than 42 were considered anxious

\begin{tabular}{lcc}
\hline & \multicolumn{2}{c}{ Anxiety score } \\
\cline { 2 - 3 } Group & $<=42$ & $>42$ \\
\hline Spinal injured & 31 & 10 \\
& $(75.6 \%)$ & $(24.4 \%)$ \\
Control & 39 & 2 \\
& $(95.1 \%)$ & $(4.9 \%)$ \\
\hline
\end{tabular}

$X^{2}=6.25 ; p<0.02, n=82$

with quadriplegia regarding anxiety and depression, though the difference on the second anxiety measure was close to significance.

From Table VI it can be seen that the only significant correlations were between the depression and anxiety measures. There was a significant relationship between the depression measures, so that high levels of depression on the initial assessment were associated with high levels on the second and third assessments. Those who were depressed on the second assessment were more likely to be depressed on the third occasion. All anxiety measures were positively intercorrelated, and those who were anxious on the second and third assessments were more likely to report anxiety and 
Table IV Chi-square analysis showing differences between the SCI and control group on frequencies of normal and abnormal depression scores. Those subjects scoring less than or equal to 14 were considered normal whilst those scoring greater than 14 were considered depressed

\begin{tabular}{lcc} 
& \multicolumn{2}{c}{ Depression score } \\
\cline { 2 - 3 } Group & $<=14$ & $>14$ \\
\hline Spinal injured & 30 & 11 \\
& $(73.1 \%)$ & $(26.9 \%)$ \\
Control & 40 & 1 \\
& $(97.5 \%)$ & $(2.5 \%)$ \\
\hline
\end{tabular}

$X^{2}=9.76 ; p<0.01, n=82$

depression on all occasions. The initial anxiety measure was significantly correlated with the first depression measure, but not the second and third occasions.

\section{Discussion}

Results demonstrated that psychological upset is a reality for a significant number of SCI persons over the first year of spinal injury. Approximately one quarter of the SCI group in this study were anxious, compared with less than $5 \%$ of controls. Approximately $25 \%$ of the SCI group were also depressed compared with around $3 \%$ of the control group. This finding is consistent with other research which has found similar levels of depression present in SCI persons. ${ }^{7-9,20}$ These findings indicate that while psychological morbidity is not an inevitable consequence of SCI, a significantly higher proportion of persons with SCI are depressed and anxious in comparison to able bodied persons of a similar background.

Although significant differences overall were found between the SCI group and

Table V Means, standard deviations and $t$ values for persons with complete and incomplete lesions. Alpha set at 0.01 due to multiple tests

\begin{tabular}{|c|c|c|c|c|c|}
\hline Var & $\underset{t}{2 \text {-tailed }}$ & $p$-level & & & $\begin{array}{l}\text { Incomplete } \\
\quad(n=13)\end{array}$ \\
\hline ANX1 & -0.45 & 0.66 & $\begin{array}{l}39.6 \\
(8.9)\end{array}$ & $\begin{array}{l}\text { mean } \\
\text { SD }\end{array}$ & $\begin{array}{l}40.9 \\
(9.2)\end{array}$ \\
\hline ANX2 & 0.36 & 0.71 & $\begin{array}{c}38.5 \\
(11.2)\end{array}$ & $\begin{array}{l}\text { mean } \\
\text { SD }\end{array}$ & $\begin{array}{c}37.2 \\
(11.5)\end{array}$ \\
\hline ANX3 & -0.71 & 0.48 & $\begin{array}{c}35.8 \\
(11.1)\end{array}$ & $\begin{array}{c}\text { mean } \\
\text { SD }\end{array}$ & $\begin{array}{c}38.5 \\
(11.8)\end{array}$ \\
\hline BDI1 & 0.01 & 0.98 & $\begin{array}{l}10.5 \\
(7.2)\end{array}$ & $\begin{array}{c}\text { mean } \\
\text { SD }\end{array}$ & $\begin{array}{l}10.4 \\
(5.4)\end{array}$ \\
\hline $\mathrm{BDI} 2$ & 0.36 & 0.72 & $\begin{array}{l}10.3 \\
(8.2)\end{array}$ & $\begin{array}{c}\text { mean } \\
\text { SD }\end{array}$ & $\begin{array}{c}9.2 \\
(9.9)\end{array}$ \\
\hline BDI3 & -0.12 & 0.90 & $\begin{array}{c}8.9 \\
(8.7)\end{array}$ & $\begin{array}{l}\text { mean } \\
\text { SD }\end{array}$ & $\begin{array}{c}9.2 \\
(9.6)\end{array}$ \\
\hline
\end{tabular}

Table VI Showing correlations between SCI patient characteristics and anxiety and depression across the three occasions

\begin{tabular}{lrrrrrrrl}
\hline Var & Age & \multicolumn{1}{c}{ Level } & \multicolumn{1}{c}{ Comp } & \multicolumn{1}{c}{ Educ } & \multicolumn{1}{c}{ BDI1 } & BDI2 & ANX1 & ANX2 \\
\hline BDI1 & 0.07 & -0.22 & -0.01 & 0.01 & 1.00 & $0.52^{*}$ & $0.84^{*}$ & $0.49^{*}$ \\
BDI2 & 0.31 & -0.12 & 0.07 & 0.09 & $0.52^{*}$ & 1.00 & 0.36 & $0.88^{*}$ \\
BDI3 & 0.23 & 0.01 & 0.02 & -0.06 & $0.52^{*}$ & $0.65^{*}$ & 0.35 & $0.60^{*}$ \\
ANX1 & -0.01 & -0.21 & 0.07 & 0.13 & $0.84^{*}$ & 0.36 & 1.00 & $0.43^{*}$ \\
ANX2 & 0.19 & -0.31 & -0.06 & 0.02 & $0.49^{*}$ & $0.88^{*}$ & $0.43^{*}$ & 1.00 \\
ANX3 & 0.16 & -0.05 & 0.11 & -0.13 & $0.52^{*}$ & $0.57^{*}$ & $0.48^{*}$ & $0.65^{*}$ \\
\hline
\end{tabular}

*significant at $p<0.01$

Level $=$ level of lesion; Comp $=$ completeness of lesion; Educ $=$ education level. 
controls on depression and anxiety, means for the SCI group on these variables do not indicate severe psychological disruption. Cook $^{21}$ found similar levels of anxiety in a group of SCI persons of whom most had been injured for less than a year. The present findings are in accord with research that suggests that severe psychological disruption is not a universal phenomenon following SCI. However, given the severity of the loss suffered, one would suspect that persons with SCI would have higher levels of depression and anxiety than able bodied persons. This was certainly the case. These responses may be considered normal responses to an abnormal situation, ${ }^{22}$ and not reflective of psychological problems usually associated with psychiatric disorders. However, some people experience more serious psychological difficulties than do others. When cut-off scores representing clinical levels of depression and anxiety were used in this study, a significantly larger proportion of SCI subjects fell into the clinically depressed and anxious category than able bodied people.

Research into psychological adjustment following SCI indicates that psychological morbidity decreases over time. ${ }^{4.17,23}$ In this study there were no significant differences in depression or anxiety across time for either the SCI or control group. These findings challenge models which suggest that people with SCI progress through a series of psychological stages, whereby the passage of time alleviates psychological distress. Not all theorists agree on the nature of the stages and the sequence in which they occur, but a common example of the stages includes shock, denial, anger, depression and acceptance. Some clinicians have postulated a 'requirement of mourning' model, ${ }^{3.4}$ which states that it is necessary for a person to mourn their loss through the display of depressive behaviour in order to adjust well to SCI. This theory was not supported by the present study. In fact, there was a positive correlation between being depressed and anxious on the initial assessment and being depressed and anxious one year following the injury. Lawson ${ }^{24}$ and Malec and Neimeyer ${ }^{25}$ found that depression during the initial hospitalisation was predictive of poor long term adjustment. The SCI subjects are being followed up for 2 years, allowing the stage theory and 'requirement or mourning' models of depression to be tested further.

One possible explanation for the stability of depression and anxiety scores across the year in this study is that adjustments are ongoing throughout the year. Thus the difficulties encountered during hospitalisation (eg lack of privacy, separation from significant others, etc) are replaced by new difficulties arising on discharge while adjusting in the community (eg physical barriers to transport, avoidance by non disabled people in social situations). Another possibility for the consistency of scores over the year is that the human spirit is resilient, and many persons with SCI are able to quickly come to terms with the loss, although mild levels of depression and anxiety are present. Medical advances in technology as well as improvements in equal employment opportunity mean that persons with SCI have increased opportunities for a good quality of life, and it is perhaps this reinforcement during hospitalisation that provides hope during the year. Whatever the case, the present study supports the increasing evidence that severe depression and anxiety are not inevitable following SCI, and that it is not necessary to display depressive behaviours in order to adjust well.

No demographic or patient characteristics were significantly correlated with anxiety or depression measures, failing to support previous research that has suggested that SCI persons with older age, low education, and having complete lesions tend to be less well adjusted. ${ }^{4,1}, 26$ However, others have found no direct age influences on psychological adjustment. ${ }^{27}$ Given the increased dependence caused by higher level lesions, one would suspect severity of injury to be associated with psychological upset. Available data does not support this belief. ${ }^{9}$ If anything, the present study found opposite trends, with SCI persons with paraplegia tending to be more anxious on the second assessment than those with quadriplegia. Although, the small sample size makes it difficult to draw firm conclusions, this finding lends some support to Hohmann's 
theory ${ }^{28}$ that the experience of emotional feelings tends to reduce on increasing level of lesion. Research has also found that persons with complete lesions tend to be more depressed than those with incomplete lesions. ${ }^{7}$ This may be due to the hope that the person with an incomplete lesion will walk again. However, there were no differences found in this study between persons with complete and those with incomplete lesions on anxiety and depression.

\section{Conclusion}

These results have implications for the treatment of persons with SCI. First, while this study shows that many people with SCI are not severely depressed or anxious, they still have elevated levels of anxiety and depression over the first year of injury. It is necessary to follow SCI persons for a longer period to determine whether this pattern remains. Subjects in this research are being followed up to 2 years post injury. Second, it is clear that up to a third of SCI persons will have levels of depression and anxiety typical of clinical depression. This would justify the provision of psychological services to assist those in need. Certainly people with disabilities advocate the need for more psychological assistance. ${ }^{29}$ Research is currently being conducted by the authors to investigate whether the provision of such treatment does enhance adjustment to SCI.

\section{Acknowledgements}

This study was supported by a grant from the Research and Development Grants Advisory Committee, Department of Community Services and Health, Canberra. Thanks go to the Staff of the spinal units of Prince Henry and Royal North Shore Hospitals Sydney, without whom this research would not be possible.

\section{References}

1 Witthower E, Gingras G, Megler L (1954) A combined psychosocial study of spinal cord lesions. Can Med Assoc J 71: 109-115.

2 Mueller A (1962) Psychologic factors in rehabilitation of paraplegic patients. Arch Phys Med Rehabil 43: $151-159$.

3 Siller J (1969) Psychological situation of the disabled with spinal cord injuries. Rehabil Lit 30: 290-296.

4 Kerr W, Thompson M (1972) Acceptance of disability of sudden onset in paraplegia. Int J Paraplegia 10: 94-102.

5 Stewart TD (1977) Coping behaviour and the moratorium following spinal cord injury. Paraplegia 15: $338-342$.

6 Craig AR, Hancock KM, Dickson HG, Martin J, Chang E (1990) Psychological consequences of spinal injury: A review of the literature. Aust NZ J Psychiatry: 398-424.

7 Fullerton DT, Harvey RF, Klein MH, Howell TH (1981) Psychiatric disorders in patients with spinal cord injuries. Arch Gen Psychiatry 38: 1361-1371.

8 Frank RG, Kashani JH, Wonderlich SA, Lising A. Visot LR (1985) Depression and adrenal function in spinal cord injury. Am J Psychiatry 142: 252-253.

9 Judd FK, Stone J, Webber J, Brown DJ, Burrows GD (1989) Depression following spinal cord injury: A prospective in-patient study. Br J Psychiatry 154: 668-671.

10 Bodenhamer E, Achterberg-Lawlis J, Kevorkian G, Belanus A, Cofer J (1983) Staff and patient perceptions of the psychosocial concerns of spinal cord injured persons. Am J Phys Med 62: 182-193.

11 Ernst FA (1987) Contrasting perceptions of distress by research personnel and their spinal cord injured subjects. Am J Phys Med 66: 182-193.

12 Cushman LA, Dijkers M (1990) Depressed mood in spinal cord injured patients: Staff perceptions and patient realities. Arch Phys Med Rehabil 71: 191-196.

13 Dijkers M, Cushman L (1990) Differences between rehabilitation disciplines in views of depression in spinal cord injury patients. Paraplegia 28(6): 380-391.

14 Trieschmann RB (1988) Spinal Cord Injuries: Psychological, Social, and Vocational Rehabilitation. New York: Pergamon Press, New York.

15 Geisler WO, Jousse AT, Wynne-Jones M, Breithaupt SD (1983) Survival in traumatic spinal cord injury. Paraplegia 21: 304-373.

16 Bartrop R, Hancock K, Craig A, Porrit D (in press) Psychosocial toxicity of bereavement. Aust Psychol.

17 Woodrich F, Patterson JB (1983) Variables related to acceptance of disability in persons with spinal cord injuries. J Rehabil 49: 26-30.

18 Beck AT, Ward CH, Mendelson M, Mock J, Erbough J (1967) An inventory for measuring depression. Arch Gen Psychiatry 4: 351-363. 
19 Spielberger CD, Gorsuch RL, Lushene RE, Vagg PR. Jacobs GA (1983) Manual for the State-Trait Anxiety Inventory. Consulting Psychologists Press, Palo Alto.

20 Judd F, Brown D, Burrows G (1991) Depression, disease and disability: Application to patients with traumatic spinal cord injury. Paraplegia 29: 91-96.

21 Cook D (1979) Psychological adjustment to spinal cord injury: Incidence of denial, depression and anxiety. Rehabil Psychol 26(3): 97-104.

22 Hohmann GW (1975) Psychological aspects of treatment and rehabilitation of the spinal injured person. Clin Orthop 112: $81-88$.

23 Richards JS (1985) Psychologic adjustment to spinal cord injury during first post-discharge year. Arch Phys Med Rehabil 67: 362-365.

24 Lawson N (1978) Significant events in the rehabilitation process: The spinal cord patient's point of view. Arch Phys Med Rehabil 59: 573-579.

25 Malec J, Neimeyer R (1983) Psychologic prediction of duration of inpatient spinal cord injury rehabilitation and performance of self-care. Arch Phys Med Rehabil 64: 359-363.

26 Frank RG, Umlauf RL, Wonderlich SA, Askanazi G. Buckelew SP, Elliot TR (1987) Differences in coping styles among persons with spinal cord injury: A cluster analytic approach. J Cons Clin Psychol 55: 727-731.

27 Frank RG, Elliott TR, Buckelew SP, Haut AE (1988) Age as a factor in response to spinal cord injury. Am J Phys Med Rehabil 67(3): 128-131.

28 Hohmann G (1966) Some effects of spinal cord lesions on experienced emotional feelings. Psychophysiology 3: $143-156$.

29 Pelletier JR, Rogers S, Thurer S (1985) The mental health needs of individuals with severe physical disability: A consumer advocate perspective. Rehabil Lit 46: 186-193. 